\title{
François Rabelais, Gargantua
}

\section{Dario Cecchetti}

\section{(2) OpenEdition \\ Journals}

\section{Edizione digitale}

URL: http://journals.openedition.org/studifrancesi/8857

DOI: $10.4000 /$ studifrancesi.8857

ISSN: 2421-5856

\section{Editore}

Rosenberg \& Sellier

\section{Edizione cartacea}

Data di pubblicazione: 1 octobre 2008

Paginazione: 439-440

ISSN: 0039-2944

\section{Notizia bibliografica digitale}

Dario Cecchetti, «François Rabelais, Gargantua», Studi Francesi [Online], 155 (LII | II) | 2008, online dal 30 novembre 2015, consultato il 13 janvier 2021. URL: http://journals.openedition.org/studifrancesi/ 8857 ; DOI: https://doi.org/10.4000/studifrancesi.8857

Questo documento è stato generato automaticamente il 13 janvier 2021.

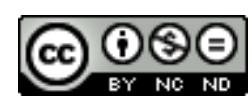

Studi Francesi è distribuita con Licenza Creative Commons Attribuzione - Non commerciale - Non opere derivate 4.0 Internazionale. 


\title{
François Rabelais, Gargantua
}

\author{
Dario Cecchetti
}

\section{NOTIZIA}

FRANÇOIS RABELAIS, Gargantua, édition présentée, établie et annotée par Mireille HUCHON, Paris, Gallimard, 2007 («Folio Classique», n. 4535), pp. 673.

1 Da quella che oggi è l'edizione rabelaisiana di riferimento, le Cuvres complètes a cura di Mireille Huchon (Paris, Gallimard, «La Pléiade», 1994), viene pubblicato in collezione economica il Gargantua (in precedenza l'operazione di scorporo e di ristampa nella collezione «Folio Classique» era avvenuta per il Quart livre). Il testo, rivisto puntualmente, è presentato con l'accompagnamento dell'annotazione, ormai imprescindibile, del precedente corpus completo, stampata nella pagina a fronte, il che fa di questa edizione un maneggevole strumento di consultazione per lo studente e per lo studioso. Si tratta - ricordiamo - non solo di un'annotazione minuziosa e chiarificatrice, sul piano concettuale e su quello lessicale, con attenzione a spiegare accuratamente giochi di parola e riferimenti oscuri, ma di un'annotazione attenta alla più recente bibliografia, che viene qui sfruttatta e citata. In appendice sono pubblicate con accurata annotazione e commento le Chroniques gargantuines (Les grandes et inestimables chroniques du grant et enorme geant Gargantua e Le vroy Gargantua), che permettono un discorso sull'archeologia' del Gargantua. Il ricco dossier contiene tavole cronologiche e uno studio sulla lingua di Rabelais. Nuova, per questa edizione, è la Préface (pp. 7-27), un interessante microsaggio che ricostruisce la complessità del Gargantua nel moltiplicarsi dei riferimenti. Il Gargantua offre tutta una serie di trasposizioni della realtà contemporanea, sotto forma di parodia e travestimento: in particolare, M. Huchon segnala le allusioni ai rapporti tra Francesco I e Carlo V e quelle allo scontro fra erasmiani e sorbonnards negli anni trenta del Cinquecento. Così, affrontando il problema dei cryptages, vede a monte della pratica 'stenografica' della scrittura rabelaisiana l'influsso dell'allegorismo quale è teorizzato da Erasmo, da sant'Agostino, da Luciano e da Macrobio, un influsso che nell'intrecciarsi di prospettive ideologiche diverse e nel moltiplicarsi delle intertestualità rende complesso il gioco 
criptico di Rabelais, gioco che trova un esito nell'ambiguità del riso, un riso «unico nel suo genere che partecipa dei très hauts sacrements e dei mystères horrifiques» di cui è questione nel prologo del Gargantua. Di fronte all'edizione modello di M. Huchon non resta che augurarsi che i restanti libri delle citate Cuvres complètes siano resi accessibili nella collezione «Folio». 